\title{
Evaluating the talking cure
}

\section{Cognitive behavioural therapy}

\author{
Megha Verma
}

\begin{abstract}
It would seem that a disorder as complex as a mental illness would require equally complex solutions. "Talking cures," known today as psychotherapies, were lauded as unscientific for a very long time. Today, cognitive behavioural therapy (CBT) is a psychotherapeutic technique that has shown considerable success in improving the prognosis for many mental illnesses using the scientific method. It is considered a panacea by some for mental illness amidst the zeitgeist of skepticism for pharmacology. This article explores the philosophical foundations of CBT and explains how a technique once considered unscientific is now the gold-standard in mental illness treatment. A randomized controlled trial (RCT) will also be discussed to examine its validity on psychotherapy and determine whether efficiency studies may be more suitable to adequately compare psychotherapies.
\end{abstract}

\section{A BRIEF OVERVIEW OF COGNITIVE BEHAVIOURAL THERAPY}

In the early 20th century, B.F. Skinner and Ivan Pavlov demonstrated how operant conditioning can alter animal behaviour. ${ }^{1}$ This research was then applied to human behaviour and developed into the current field of behavioural therapy (BT). ${ }^{1}$ BT is a "non-mediational" approach, meaning that it deals in measurable variables. This was a revolutionary technique at the time that would go on to dominate the field of psychiatry for decades, while cognitive behavioural therapy (CBT) was naught but a heterodox afterthought. However, the pitfalls of BT soon became apparent. First, it did not work for all patients and disorders (most prominently with depression). Second, the behaviour model did not explain why patients receiving treatment for a specific phobia saw improvements to other aspects of their mental state when they were not specifically targeted. ${ }^{2}$

These shortcomings permitted a new type of therapy to rise to prominence, one that focused on unmeasurable, "mediational" variables that determine behaviour. Much like Paul Simon's solo career, however, it was not until the mid 1970's when CBT really blossomed due to Beck's advent of unconscious "schemas" that may be altered. ${ }^{3}$ Significant clinical success in improving patient prognosis was immediately forthcoming in panic disorders, ${ }^{4}$ generalized anxiety, ${ }^{5}$ eating disorders, ${ }^{6}$ and schizophrenia. ${ }^{7}$ These results have proven to be robust and generalizable, thanks to a litany of modern-day replications. CBTs are unique among established psychotherapies because they help patients manage symptoms to become more functional, rather than trying to resolve issues underlying their diathesis to mental illness in the first place. In this manner, patients can carry out activities of daily living and achieve a greater degree of independence in their life.

There are three major components of CBTs: coping skills therapies, problem solving therapies, and cognitive restructuring therapies. The goal of CBT is to teach patients how to become aware of their dysfunctional perception of reality, and to be more objective and rational in their perceptions. Because of these sustainable coping skills, CBT has proven to produce more favourable longterm outcomes than pharmacology alone. ${ }^{8}$ Due to the involved nature of CBT, such as the homework given to patients, adjuvant pharmacotherapy is typical of treatment plans in moderate to severe cases. The drugs help patients better adhere to therapy.

Stoic philosophy underlies much of the cognitive model. Much like CBT, the stoics assert the value of disengaging one's emotions from experiences so that we may evaluate them more objectively. Furthermore, stoicism emphasizes thinking about a situation in terms of actionable goals rather than dwelling too much on the past or the future. The prescriptions in Marcus Aurelius' "Meditations" read much like the cognitive processes CBT therapists strive to help patients adopt. Epictetus sums up the core of stoic philosophy:

[They are] not the external events that cause us distress, but the way in which we think about them...Our attitudes and reactions that give us trouble. We cannot choose our external circumstances, but we can always choose how we respond to them. ${ }^{9}$

\section{THE NEUROSCIENCE OF CBT}

It has been shown that CBT may alter the brain via mechanisms that are physiologically measurable. The prefrontal cortex (PFC) of the brain functions to understand the world in a rational way and regulates emotional responses. It exerts an inhibiting effect on limbic regions of the brain, such as the amygdala, that are associated with emotional responses. Reduced PFC activity results in reduced inhibitory effects on the amygdala and thus greater emotional reactivity. A study on 26 patients suffering from social anxiety disorder measured treatment-related changes in brain structure. ${ }^{10}$ They found that patients who received CBT had reduced grey matter volume in the amygdala, and had decreased anticipatory anxiety before a public speaking task. Similarly, it was found that patients with bipolar disorder had reduced functional connectivity between the amygdala and inferior frontal gyrus (an area of the PFC) compared to healthy controls. ${ }^{11}$ This indicates that CBT therapy may be successful as it helps to develop functions related to the PFC, such as objective appraisals of one's environment. A systematic review of imaging studies for depression also showed improved PFC activity as approximated 
from functional magnetic resonance imaging. ${ }^{12}$ However, links to behavioural changes must be made to substantiate these data.

\section{EFFICACY}

Clinical evidence unequivocally corroborates the usefulness of CBT for many disorders, such as bipolar, ${ }^{13}$ obsessive-compulsive, and generalized anxiety disorder. ${ }^{14,15}$ It has been clinically demonstrated that CBT entails greater reduction in anxiety and depression at 6 months post-treatment compared to supportive therapy. ${ }^{16}$ In a meta-analysis of 124 studies on panic disorder, introducing cognitive elements to traditional behaviour therapy led to lower rates of attrition. ${ }^{17}$ CBT has also been shown to have long-term benefits for people at risk of developing posttraumatic stress disorder if it is administered within one month after an initial trauma. ${ }^{18}$ CBT certainly shows promise for treating a variety of disorders and patients, but the caveats cannot be ignored. Compared to physical illnesses, mental illness presents a much greater degree of prodrome idiosyncrasy. As such, a single treatment cannot be easily generalized and prescribed to the entire population.

Randomized controlled trials (RCTs) are considered the most reliable evaluation of medical treatments. This type of trial permits the researcher to faithfully determine a causal relationship between treatment and outcome due to the fastidious elimination of confounding variables. These types of studies have been adapted from those designed to evaluate pharmacological treatments where the controlled criteria are more realistically modelled. As a result, RCTs for pharmacological drugs are easier to conduct than for CBT in terms of determining therapeutic drug doses and classifying subpopulations for different treatment strategies.

By its very nature, however, psychotherapy cannot be precisely dosed and prescribed. As such, clear causal relationships cannot be extracted from trials without entirely sacrificing external validity. Furthermore, mental health patients often present with comorbidities that require a specialized therapeutic repertoire that is tailored, customized, or otherwise unique to that specific patient. A study on the degree to which different psychotherapeutic techniques adhered to therapeutic strategies was evaluated in the National Institute of Mental Health (NIMH) treatment of depression program in 2002. The screening of psychiatrist-patient transcripts showed that psychiatrists adhered more to the CBT prototype instead of other prototypes in both the CBT group and the interpersonal therapy group. ${ }^{19}$ The original NIMH study reported that there was no significant difference between CBT therapy and interpersonal therapy. However, this assessment of the transcripts clearly reveals that both groups were in fact CBT groups. The authors reported that:

[...] similarities in process across treatments help explain the lack of differential outcomes frequently observed in trials of psychotherapy. What are often referred to as nonspecific effects in the literature may actually represent the specific effects of shared process. ${ }^{19}$

It has been shown that efficiency studies rather than efficacy studies (ie. RCTs) may be more useful in teaching us about the benefit of a particular psychotherapeutic treatment. Efficiency studies treat each psychotherapeutic intervention as one component of treatment, and studies evaluate the degree to which the added therapy improves patient outcome compared to treatment as normal. It reports outcomes for a preexisting and representative patient population. Consequently, the results of efficiency studies of psychotherapies are more applicable to real-life clinical situations. The future of psychotherapy research should focus more on efficiency studies, as the scientific methods that evaluate pharmacology do not necessarily translate well to psychotherapy.

\section{ACCESSIBILITY}

The increasing prevalence of mental illnesses and the demonstrated efficacy of CBT in studies suggests that CBT should be made more widely accessible. The preventative and long-term orientation of CBT would actually save the health care system money in the long run. One logistical hurdle to the implementation of CBT is the paucity of trained therapists.

Effective CBT requires at least 12 sessions to make the treatment both economically and logistically attractive to patients compared to other, prolonged therapies. Internet-based CBT (iCBT) may be one way to improve accessibility and is particularly salient to patients living in remote areas. No significant difference was found between iCBT and face-to-face CBT in a study of 86 panic disorder patients, and both therapies produced significant reductions in clinician severity ratings. Additionally, iCBT was $35 \%$ faster than face-to-face therapy. ${ }^{20,21}$

\section{CONCLUSION AND FINAL REMARKS}

There is a non-trivial mental health crisis around the world. As governments and organizations commit ever greater sums of money in the wake of the increasing death-toll from mental illness, it is the duty of scientists and physicians to determine where this money should be invested. Clearly, CBT is not only a buzzword. Increasing the quality of treatment through efficiency studies and improving accessibility of treatment is our best hope to mitigate this pandemic.

\section{REFERENCES}

1. Dobson KS, Dozois DJ. Handbook of cognitive-behavioural therapies. 4th ed. New York (NY): Guilford Publications; 2009.

2. Bandura A. Principles of behaviour modification. New York (NY): Holt, Reinhart \& Winston; 1969.

3. Beck AT. Cognitive therapy: a 30-year retrospective. Am Psychol. 1991 Apr;46(4):368-75. https://doi.org/10.1037/0003-066X.46.4.368

4. Beck AT. Cognitive approaches to panic disorder: theory and therapy. In: Rachman S, Maser J, editors. Panic: Psychological perspectives. Hillside, NJ: Erlbaum; 1987. p. 91-109.

5. Butler G, Fennell M, Robson P, et al. A comparison of behaviour therapy and cognitive theory in the treatment of generalized anxiety disorder. J Consult Clin Psychol. 1991 Jan;59(4):167-75. https://doi. org/10.1080/09515070802602096

6. Garner DM, Bernis KM. A cognitive-behavioural approach to anorexia nervosa. Cognit Ther Res. 1982 Jun;6:123-50. https://doi.org/10.1007/ BF01183887

7. Perris C. Cognitive therapy with schizophrenics. New York (NY): 


\section{FEATURE ARTICLE}

Guilford Publications; 1988.

8. Gloaguen V, Cottraux J, Cucherat M, et al. A meta-analysis of the effects of cognitive therapy in depressed patients. J Affect Disord. 1998 Apr;49(1):59-72. https://doi.org/10.1016/S0165-0327(97)00199-7.

9. Epictetus. The Enchiridion. Translator unknown. 55-132 AD.

10. Mansson KN, Salami A, Frick A, et al. Neuroplasticity in response to cognitive behaviour therapy for social anxiety disorder. Transl Psychiatry. 2016 Feb;6:e727. https://doi.org/10.1038/tp.2015.218

11. Li M, Huang C, Deng W, et al. Contrasting and convergent patterns of amygdala connectivity in mania and depression: a resting-state study. J Affect Disord. 2015 Mar;173:53-8. https://doi.org/10.1016/j. jad.2014.10.044

12. Franklin G, Carson AJ, Welch KA. Cognitive behavioural therapy for depression: systematic review of imaging studies. Acta Neuropsychiatr. 2016 Apr;28(2):61-74. https://doi.org/10.1017/neu.2015.41

13. Milkowitz DJ, Otto MW. Psychosocial treatments for bipolar depression: a 1-year randomized trial from the systematic treatment enhancement program. Arch Gen Psychiatry. 200 Apr;64(4):419-26. https://doi.org/10.1001/archpsyc.64.4.419

14. Hunot V, Churchill R, Silva de Lima M, et al. Psychological therapies for people with generalised anxiety disorder. Cochrane Database Syst Rev. 2007 Jan;1:CD001848. https://doi.org/10.1002/14651858. CD001848.pub4

15. Hofmann GS, Asnaani A, Vonk I, et al. The efficacy of cognitive behavioural therapy: a review of meta-analyses. Cognit Ther Res. 2012 Jul;36(5):427-40. https://doi.org/10.1007/s10608-012-9476-1

16. Bandelow B, Seidler-Brandler U, Becker A, et al. Meta-analysis of randomized controlled comparisons of psychopharmacological and psychological treatments of anxiety disorder. World J Biol Psychiatry. 2007 Jul;8(3):175-87. https://doi.org/10.1080/15622970601110273

17. Mitte K. A meta-analysis of the efficacy of psycho-and pharmacotherapy in panic disorder with and without agoraphobia. J. Affect Disord. 2005 Sep;88(1):27-45. https://doi.org/10.1016/j. jad.2005.05.003

18. Bryant RA, Moulds ML, Nixon RV. Cognitive behaviour therapy of acute stress disorder: a four-year follow-up. Behav Res Ther. 2003 Apr;41(4):489-94. https://doi.org/10.1016/S0005-7967(02)00179-1

19. Albon JS, Jones EE. Validity of controlled clinical trials in psychotherapy: findings from the NIMH treatment of depression collaborative research program. Am J Psychiatry. 2002 May;159(5):775-83. https://doi.org/10.1176/appi.ajp.159.5.775

20. Carlbring P, Ekselius L, Anderson G. Treatment of panic disorder via the Internet: a randomized trial of a self-help program. J Behav Ther \& Exp Psychiat. 2003 Jun;34(2):129-40. https://doi.org/10.1016/S00057916(03)00026-0

21. Kiropulos LA, Klein B, Austin DW, et al. Is internet-based CBT for panic disorder and agoraphobia as effective as face to face CBT? J Anxiety Disord. 2008 Dec;22(8):1273-84. https://doi.org/10.1016/j. janxdis.2008.01.008 